\title{
MOVING THROUGH SPACES - LEISURE WALKING AND ITS PSYCHO- SOCIAL BENEFITS FOR WELL-BEING: A NARRATIVE REVIEW
}

review paper

( ) University School of Physical Education in Wroclaw

DOI: https://doi.org/10.5114/hm.2020.89908

\section{MARTA ANNA ZURAWIK}

Independent researcher

\begin{abstract}
Leisure walking provides an escape from routines and daily lives, and offers positive experiences, such as fascination with nature, reflection, and mental relaxation. The processes of exploring and observing nature while walking build bonds between people and spaces. In walking, people explore personal capabilities and overcome challenges associated with demanding landscapes, which enhances feelings of satisfaction and achievement. Furthermore, sharing spaces and similar positive experiences with others while walking promote social interactions and a sense of belonging that combats feelings of loneliness and benefits well-being. Ample research on physical activity, including walking, has explored the role of psychological, social, and environmental factors in the activity participation, and recognised its benefits for mental health and well-being. This paper reviews literature in the field of leisure and environmental psychology to present the evidence of the positive relationships between leisure walking in the natural environment and its psychological and social benefits for well-being. Key words: leisure walking, nature, social well-being, mobility, therapeutic landscapes, mental well-being
\end{abstract}

\section{Introduction}

Walking is an ordinary and natural human activity like breathing, sleeping, and eating. It is also a common form of daily physical activity. Morris and Hardman [1] describe it as being the nearest to a perfect exercise, since it does not require any type of formal training or special equipment and can be performed at any convenient time and place [2, 3]. Walking can be undertaken intentionally, for example for recreation, to satisfy the need for social contact and fitness, or to achieve exercise requirements. It can also be incidental when performed while being active for another purpose, such as walking for transportation (commuting to work or school), utilitarian walking (shopping), and leisure walking (while playing golf).

The concept of walking is complex and can be viewed from various perspectives. From a physiological standpoint, walking is a rhythmic, dynamic, aerobic exercise that uses large muscle groups of legs, limb girdle, and lower trunk, and can be practised at various intensity levels [1]. However, considering walking only as a bodily exercise, i.e. an instrument for improving physical health and fitness, reduces its meaning. Walking is much more than a capacity of a biological organism. It plays an important role in the mental and social functioning of people, as it is a socially constructed behaviour, a specific and unique system of communicating that depends upon individual intentions and distinctive qualities of spaces.

\section{Walking through the spaces}

Rhythms and styles of walking uncover and connect people with places. The relationship between people and various spaces is multi-sensory and unique for everyone in terms of textures, sights, sounds, and smells [4]. Wunderlich [5] suggests that while moving through space, people unavoidably touch and feel the environment with their entire bodies.

Place is a core concept of environmental psychology, and a rich body of literature has shown that the nature of attachment to places can be considered in different ways: affective, cognitive, and conative. Person-place bonding requires a positive emotional connection to a place, for instance love or contentment, cognitive ele-

Correspondence address: Marta Anna Zurawik, 2 Wilson Avenue, Wigan WN6 7HD, United Kingdom,

e-mail:martazurawik@hotmail.com

Received: October 22, 2018

Accepted for publication: August 17, 2019

Citation: Zurawik MA. Moving through spaces - leisure walking and its psycho-social benefits for well-being: a narrative review. Hum Mov. 2020;21(2):1-8; doi: https://doi.org/10.5114/hm.2020.89908. 
ments, such as memories, beliefs, meaning and knowledge that individuals associate with the particular place, and expressed actions of returning to the place [6].

Prior studies on person-place bonding have proposed similar concepts such as place rootedness, sense of place, place identity, and place attachment. Although these terms differ, there is agreement in the literature that the concepts are related.

Place attachment is characterised as a positive affective relationship between a person or a group and a place; the relationship makes a specific place a part of conceptual and extended self. The concept consists of two dimensions: place identity and place dependence. Place dependence is a level to which individuals perceive themselves as functionally associated with places. Place identity is characterised as a combination of values, attitudes, thoughts, beliefs, meanings, and behaviours reaching beyond emotional attachment and belonging. Years later, Scannell and Gillford [6] revisited the concept and proposed a framework of place attachment consisting of three dimensions: person, place, and process.

The person dimension involves personal connection with a place evoked by memories of meaningful experiences, personal milestones, and symbolic meanings of the place. In the study of walking a pilgrimage, Danely [7] explored deep psychological and somatic relationships with the landscape and the values of physical self-reliance, mental discipline, and spiritual serenity of movement through outdoor spaces.

The place dimension is divided into two levels: social and physical attachment. At the social level, attachment is often characterised as a sense of place - a collection of symbolic meanings of a place and satisfaction with settings through which people acquire a sense of belonging, sense of community, and rootedness. For instance, group leisure walks enhance a sense of fellowship by meeting people with similar shared interests and leisure pursuits. The physical attachment of a place refers to physical settings, the built environment, and the natural environment that provide amenities and resources to support the individual goals [6].

Several studies suggested that walking was associated with areas of a greater number of destinations within the walking distance, higher levels of mixed land use, safety of the environment, and access to open spaces [8]. The process dimension links the person and place dimensions in order to express positive actions and behaviours related to the place.

The literature on place identity posits that the concept is characterised as a combination of values, attitudes, thoughts, beliefs, meanings, and behaviours reaching beyond emotional attachment and belonging. Scholars suggest that place identity carries two meanings: the first one refers to the features of the place that guarantee its distinctiveness, the second one is where place is a means to distinguish oneself from others in order to create self-esteem [9]. The meanings of spaces are not universally shared. Walking styles and rhythms indicate and develop social and cultural identities, positions, or rankings in the society, which can be noticed within particular environments, such as schools, hospitals, the army, and various sub-cultural groups [10]. The individual meaning for a given physical setting indicates what should happen in it, what the setting is supposed to be like, and how the individuals are supposed to behave in it. Beyond knowing how to behave and what to expect from particular settings, the environmental meaning includes symbolic and affective associations between individuals and various aspects of the physical environment.

In this view, individual walking rhythms can be identified, represented, and regulated by the 'gaze' a construction of signs, characteristics of everyday life, which enable people to determine time and space, differentiate between leisure and non-leisure time and space, and decide what behaviours and symbolic images are appropriate for given situations [11]. For instance, people walk differently in busy streets, shopping malls, parks, or beaches, as well as at various times of day, weather, or season [12]; with increasing leisure time and mobility, the natural environment is made accessible to a large number of people to practise various types and rhythms of walking.

Furthermore, an important function of place identity is the environmental past, recognising what is familiar or unfamiliar, against which any immediate physical settings can be judged and understood.

The concepts of place attachment and place identity are often linked to the recreational literature, since human bonding with recreational spaces is a common occurrence. Human bonding with recreational places involves such factors as characteristics of the physical environment, human experience and use of the environment, social, psychological, and cultural interpretation and constructed meanings of people-place interactions. In other words, recreationalists search for aesthetic and natural environments and use special and unique settings and landscapes that can satisfy their leisure needs. As a result, they develop an emotional bond, a sense of familiarity and close connections with these places.

Based on this diverse literature, Hammitt et al. [13] developed five dimensions of place bonding for rec- 
reational spaces where people develop cognitive and affective attachment to places: place dependence, place familiarity, place belongingness, place rootedness, and place identity.

Place dependence refers to the potential of a place to satisfy the needs and fulfil the goals of individuals. It suggests loyalty and relies on a broad range and functionality of recreation settings that facilitate leisure behaviours. Place dependence is an important dimension for walking since the enjoyment of walking depends on meaningful aspects of the built and natural environments such as parks, trails, forests, lakes that satisfy walking needs and desires and promote experiencing specific leisure walking outcomes, such as relaxation, contemplation, and a sense of escape. In particular, ramblers and pilgrims enjoy the experience of moving outdoors in attractive environments to achieve healthy physical and spiritual sensations [10]. Slavin [14] emphasised the importance of reflexive walking, the rhythmic activity of the motion that enhanced the meditative aspect of a pilgrimage. According to him, the pilgrims' goal is not reaching their destination, but the spiritual experience of 'being on the way'.

Place familiarity involves pleasant memories, achievement memories, and environmental images that result from remembrances associated with recreational spaces. It offers a frame of reference where individuals feel secure, stable and perceive themselves as a part of the environment. Places visited during leisure walks are often self-selected and thus result in memories that provide affectionate experiences and promote bonding with these places. Through walking, people experience places as an opportunity for exercising and socialising, which creates unique place experiences, memories, and meanings. Moreover, by noticing landmarks and routes, walkers have feelings of being part of the landscape. While moving and connecting views and feelings and places, walkers obtain a new perspective of a place and a strong knowledge base for familiarity of places and a sense of emotional security [15].

Place belongingness suggests a strong level of connectivity and affiliation with a place and familiarity that may develop into a communal bond between people and places. Place belongingness also entails communal connections towards environments, which are shared with family and friends. In particular, walking creates a sense of intimacy by sharing the space with others, which often provides a context for social relationships, social support, and social bonding.

Place rootedness is an intense level of place bonding, where people become settled to a degree that they have little desire for another place. There is recreational genealogy associated with the places rooted in family members, lasting friendships, activities, and stories from the past. Long-term walkers may speak of some walking routes and destinations as a home place, which is the centre of meaningful activities, interactions, and stories from the past.

Place identity is a combination of values, beliefs, thoughts, and meaning. Relationships between place identity and recreation help individuals create and affirm a sense of self. Recreational spaces that also satisfy needs may be viewed as an essential part of oneself, which results in strong psychological and affective bonds to places. Researchers have emphasised the identity and symbolic meanings developed in outdoor places. The recognition and meaning of place identity can be facilitated by walking as an embodied way of understanding individual relationships with a place. Walking is a mode of experiencing places, developing feelings and thoughts for them [5]. Moreover, it is an act of the exploration of the self.

Place identity perceives walking as an end itself because it emphasises awareness of the self and synchronises inner (body and mind) and outer (social, collective) paces and rhythms as an experience of being exposed to natural and urban surroundings [11, 14]. In particular, walking in pleasant and calm landscapes enhances aesthetical awareness, diverts attention from negative emotions and thoughts, and provides opportunities for meaningful physical activity and recreation [4].

\section{Walking as a leisure activity}

The general and dichotomous categorisation of leisure conceptualises it as objective and subjective. An objective standpoint characterises leisure as free time or an activity which is associated with pleasant feelings. Leisure as free time is orientated towards pursuits of freely chosen recreational activities that satisfy personal needs and provide intrinsically rewarding experiences after complying with occupational, family, household, socio-spiritual, and socio-political obligations. Leisure activities focus on the quantity of participation and on the environment in which leisure takes place. Leisure behaviours occur in discretionary time, during voluntary activities, which offer no material gain and provide meaningful and satisfying experiences [16]. In contrast, a subjective approach interprets leisure as a state of mind or experience associated with freedom of choice, intrinsic motivation, psychological functions, enjoyment, relaxation, and commitment. However, perceiving leisure only as time, 


\section{HUMAN MOVEMENT}

M. Zurawik, Moving through spaces: a narrative review

behaviour, or experience does not provide sufficient definitions of leisure. Leisure occurs outside of work, which suggests the mental state of leisure is inseparable from behaviour, and leisure behaviour and experience are an interplay of internal psychological dispositions, such as feelings, beliefs, attitudes, needs, personality characteristics, and situational influences and norms. As a result, leisure can be defined as a mental state that occurs in free time during voluntary activities on the basis of personal interests; it is intrinsically satisfying, pleasurable, and pursued for individual rewards.

Watkins [17] created a continuum of five leisure dimensions of the intentional change in leisure meanings. His theoretical framework consists of two premises. First, leisure experiences are perceived as internal relations between individuals and their leisure involve- ment. Second, leisure experiences can be ordered as a sequence of meanings according to increasing levels of complexity. More developed meanings demonstrate a greater diversity in dimensions forming the leisure experiences, increasing flexibility in the temporal organisation of dimensions, and higher levels in integration between leisure and other areas of life [17]. The progress of leisure meanings arises from experiencing leisure as passing time, exercising choice, escaping pressure to achieving fulfilment. The five dimensions highlight the inter-connected nature of leisure experiences relating to time, motivation, behaviour, emotions, and leisure functions. These leisure meanings can be referred to leisure walking as it is a diverse and dynamic activity with a wide spectrum of recreational options and purposes that range from occasional spontaneous short walks and daily strolls to chal-

Strenuous, rigorous, planned, challenging, rewarding, unconventional, for aficionados

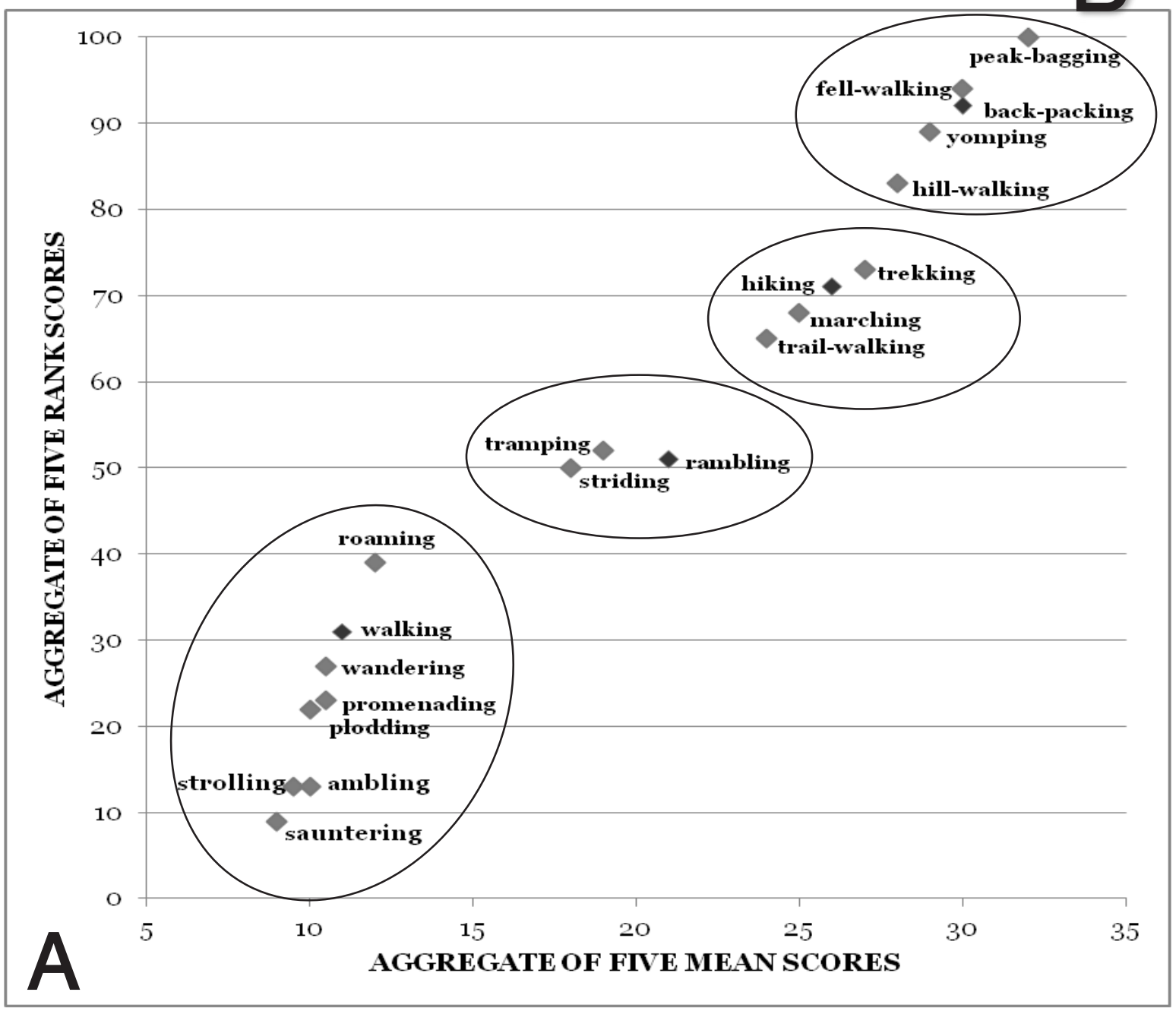

Easy, casual, spontaneous, relaxing and sociable, conventional, mainstream, mixed ability groups

Figure 1. Twenty types of leisure walking. Source: [18] 
lenging trekking and planned back-packing walks. Kay and Moxham [18] classified 20 types of walking based on five sets of walking dimensions: (1) casual strenuous; (2) mixed-ability group - aficionados; (3) spontaneous - planned; (4) relaxing, sociable - challenging, rewarding; (5) mainstream - minority. With these categories, walking activities were grouped into five clusters (Figure 1).

Watkins [17] conceptualised changes in leisure meanings from passing time to exercising choice, indicating the increased relevance of leisure in personal life and desire for personal choice and control in establishing and reinforcing leisure identity. Experiencing leisure as asserting control changes leisure meanings from escaping pressures to forgetting about problems. In this view, the intentions of participation in casual, relaxing, and sociable walking activities, such as strolling, wandering, and roaming, focus on taking time to regain control, detaching from the source of pressure to forget problems and restore balance in life.

In contrast, changing leisure meanings from passing time to exercising choice by displaying competence - acquiring knowledge and skills, and establishing goals - indicates understanding leisure as an opportunity for personal growth and extending awareness beyond personal needs in order to escape pressure and understand problems. Individuals who participate in strenuous and challenging walking activities that require planning and preparation, such as hill-walking, back-packing, and peak-bagging, recognise leisure as a means of self-development and achieving fulfilment. These demanding walking activities extend recreational walking into the outdoor pursuits that offer freeing the mind of distractions to focus on the moment, building connections with people and places as opportunities for enhancing personal well-being.

\section{Psychological and social well-being benefits of leisure walking}

There is a clear distinction between free time and leisure. Leisure occurs during free time; however, not all free time is leisure. Free time is leisure when it involves activities that provide relaxation, entertainment, personal development, and spiritual renewal. Moreover, unlike free time activities, leisure activities enhance both subjective and psychological well-being through meaningful and pleasurable experiences [19]. The relationship between leisure and subjective well-being can be found in opportunities to escape from everyday life problems and negative emotions, as well as learn how to cope with stressful situations by becom- ing involved in and achieving satisfaction from leisure experiences [20]. Regular participation in leisure activities also influences psychological well-being by developing self-determination, promoting self-restoration, providing unique opportunities for commitment and developing skills [21].

The literature suggests that the outdoor leisure time physical activity offers contexts for many types of positive experiences. A body of research shows that being outdoors in the natural environment is beneficial. Ettema and Smajic [22] reported that the natural environment fostered positive emotions. Gidlow et al. [23] observed that walking in the natural environment for at least 30 minutes conferred greater benefits for restorative experiences and cognitive functions when compared with walking in the pleasant urban environment. The positive effects of nature have been explained by various theories and approaches, such as therapeutic landscapes [24] and attention restoration [25].

The concept of therapeutic landscapes is based on the premise that particular landscapes can provide the settings for therapeutic activities, which are associated with healing. The beneficial effects of attractive landscapes focus on emotional bonds between people and spaces, as well as physical and mental engagement with the environment through sensory experiences and people's sense of place. The main role of therapeutic landscapes is to capture people's attention, enhance aesthetical awareness, and divert focus from negative emotions and thoughts. Attractive landscapes satisfy the human need for cultural roots and provide opportunities for meaningful activities and self-development, which are related to health and psychological wellbeing [26].

Similar to the concept of therapeutic landscapes, the attention restoration theory posits that natural spaces facilitate the restoration of attention capacities by providing activities that require prolonged effortless attention. 'Natural settings are equipped to facilitate restorative processes, because they are filled with innately fascinating and aesthetically pleasing stimuli' [27, p. 686]. Many aspects of the natural environment, such as the diversity in landscape, vegetation patterns, wildlife, sunrise, sunset, contain a great degree of fascination, affording an arousal and attentive state that is effortless. Therefore, restorative environments need to contain fascinating objects and events and provide opportunities for exploration and discovery that also allow for being away from everyday demands and problems.

The literature $[25,28]$ has proposed that prolonged exposure to the natural environment offers relief from stress and mental fatigue in settings that evoke moder- 
ate levels of interest, pleasantness, calmness, and reflective thoughts due to the following properties: (1) the experience of being away from daily routines and distancing oneself from problems; (2) a soft fascination with natural settings, which provides opportunities for reflection and effortless attention, thus allowing direct attention to rest; (3) the extent of the environment, which allows exploration, a sense of engagement, and a sense of belonging; (4) the compatibility between the environment and one's purposes, which supports intended leisure activities.

There is ample evidence to suggest that walking in natural environments benefits psychological wellbeing. Therapeutic effects of walking for leisure are expressed in the concepts of 'walking - cure,' 'psychotherapeutic walking,' or 'therapeutic mobilities' [29], which suggest that all individuals can walk their way into physical health and mental well-being.

Walking therapy may lie in a solitary walk or the company of others [30]. For many people, a solitary walk in the natural environment is preferable as it allows for a closer communion with nature. In the solitude, individuals seek to withdraw from complex social environments, which they have little control over. Thus, lone walking provides an enjoyable antidote to stress and mental fatigue through engagement with the physical environment - aesthetical awareness, fascination with the countryside, the experience of being away from daily routines, and distancing oneself from daily stresses and problems [28].

Solitary walking also encourages a reflective appreciation of surroundings and cultural contextualisation of the countryside. This preference was given much credence, as it was practised, theorised, and used through the Romantic Movement of the late $18^{\text {th }}$ century. The essayist William Hazlitt wrote [31, p. 326]:

One of the pleasantness things in the world is going on a journey; but I like to go by myself. I can enjoy society in a room; but out of doors, nature company is enough for me. I am then never less alone than when alone.

Also, Hunt [32] suggested that landscape provoked an unfocused or diffuse state in which anything and everything can enter the mind rather than aspects or images of the landscape in which the solitary walk occurs. Nonetheless, walking as a shared experience is therapeutic. Much research has emphasised the significance of the social world in the participation in leisure walking, arguing that the opportunities for socialising and social support are the strongest predictors for walking in various population samples [33]. In particular, group leisure walking nurtures collec- tive values of companionship and aesthetical appreciation of nature. Group walking is a form of togetherness, even when one is alone among strangers, because it allows walkers to establish and maintain an intimacy and familiarity with the community and create a sense of belonging to a special group, which with time may become a centre of one's social life. Group walks in natural environments can have an effect on well-being greater than solitary walking as they provide social settings for interactions, developing and strengthening friendships, expressing and sharing interests. This form of supportive sociality and emotional closeness combats feelings of loneliness and isolation, which can have significant benefits for social well-being [34].

\section{Conclusions}

The exploration of the relationships between humans and the environment brought attention to the social, cultural, and physical contexts of relations between people and places, which enhance both social and mental wellness.

The popularity of leisure walking provides an opportunity to promote walking as a therapeutic recreation that benefits psycho-social aspects of well-being through meaningful and pleasurable experiences of bonding people with places.

The relationships between leisure walking and social and mental well-being can be found in the opportunities to escape everyday life problems and negative emotions by finding a seclusion and peacefulness in nature. In particular, the aesthetic beauty of places, the lack of built environment, and the abundance of natural diversity tend to be perceived as sources of fascination, appreciation, and mental relaxation.

The interactions with nature also provide opportunities for exploring personal capabilities and developing skills which contribute to feelings of personal control and satisfaction. For instance, the experiences of overcoming natural challenges, such as muddy and slippery paths, or mental challenges, such as fatigue, provide feelings of achievement that enhance a sense of well-being. Furthermore, walking in aesthetically pleasant natural settings offers collectively shared restorative experiences. Moving through the space, sharing fascination and appreciation of the places with others results in a sense of intimacy and inclusion which diminishes feelings of loneliness and isolation.

\section{Ethical approval}

The conducted research is not related to either human or animal use. 


\section{Disclosure statement}

The author does not have any financial interest and did not receive any financial benefit from this research.

\section{Conflict of interest}

The author states no conflict of interest.

\section{References}

1. Morris JN, Hardman AE. Walking to health. Sports Med. 1997;23(5):306-332; doi: 10.2165/00007256199723050-00004.

2. Darker CD, French DP, Eves FF, Sniehotta FF. An intervention to promote walking amongst the general population based on an 'extended' theory of planned behaviour: a waiting list randomised controlled trial. Psychol Health. 2010;25(1):71-88; doi: 10.1080/0887044 0902893716.

3. Wensley R, Slade A. Walking as a meaningful leisure occupation: the implications for occupational therapy. Br J Occup Ther. 2012;75(2):85-92; doi: 10.4276/030 802212X13286281651117.

4. Milligan C, Gatrell A, Bingley A. "Cultivating health”: therapeutic landscapes and older people in northern England. Soc Sci Med. 2004;58(9):1781-1793; doi: 10.1016/S0277-9536(03)00397-6.

5. Wunderlich FM. Walking and rhythmicity: sensing urban space. J Urban Design. 2008;13(1):125-139; doi: 10.1080/13574800701803472.

6. Scannell L, Gillford R. Defining place attachment: a tripartite organizing framework. J Environ Psychol. 2010;30(1):1-10; doi: 10.1016/j.jenvp.2009.09.006.

7. Danely J. A watchful presence: aesthetics of well-being in a Japanese pilgrimage. Ethnos. 2015;1-28; doi: 10.1080/00141844.2015.1045916.

8. Feuillet T, Salze P, Charreire H, Menai M, Enaux C, Perchoux $\mathrm{C}$, et al. Built environment in local relation with walking: why here and not there? J Transport Health. 2016;3(4):500-512; doi: 10.1016/j.jth.2015.12.004.

9. Lewicka M. Place attachment, place identity, and place memory: restoring the forgotten city past. J Environ Psychol. 2008;28(3):209-231; doi: 10.1016/j.jenvp.2008. 02.001 .

10. Green J. 'Walk this way': public health and the social organization of walking. Soc Theory Health. 2009;7(1): 20-38; doi: 10.1057/sth.2008.19.

11. Vergunst J. Rhythms of walking: history and presence in a city street. Space Cult. 2010;13(4):376-388; doi: 10.1177/1206331210374145.

12. Edensor T. Walking in rhythms: place, regulation, style and the flow of experience. Vis Stud. 2010;25(1): 69-79; doi: 10.1080/14725861003606902.

13. Hammitt WE, Kyle GT, Oh C-O. Comparison of place bonding models in recreation resource management. J Leis Res. 2009;41(1):57-72; doi: 10.1080/00222216. 2009.11950159 .
14. Slavin S. Walking as spiritual practice: the pilgrimage to Santiago de Compostela. Body Soc. 2003;9(3):118; doi: 10.1177/1357034X030093001.

15. Lund K. Landscapes and narratives: compositions and the walking body. Landsc Res. 2012;37(2):225237; doi: 10.1080/01426397.2011.651111.

16. Kelly JR. Leisure, $4^{\text {th }}$ ed. Urbana: Sagamore Publishing; 2012.

17. Watkins M. Using intentional attributes to explain change in leisure meanings. Leis Sci. 2013;35(2):89106; doi: 10.1080/01490400.2013.761900.

18. Kay G, Moxham N. Paths for whom? Countryside access for recreational walking. Leis Stud. 1996;15(3):171183; doi: 10.1080/026143696375594.

19. Newman DB, Tay L, Diener E. Leisure and subjective well-being: a model of psychological mechanisms as mediating factors. J Happiness Stud. 2014;15(3):555578; doi: 10.1007/s10902-013-9435-x.

20. Stenseng F, Rise J, Kraft P. Activity engagement as escape from self: the role of self-suppression and selfexpansion. Leis Sci. 2012;34(1):19-38; doi: 10.1080/ 01490400.2012 .633849$.

21. Ábrahám J, Velenczei A, Szabo A. Perceived determinants of well-being and enjoyment level of leisure activities. Leis Sci. 2012;34(3):199-216; doi: 10.1080/ 01490400.2012 .669677$.

22. Ettema D, Smajic I. Walking, places, and wellbeing. Geogr J. 2015;181(2):102-109; doi: 10.1111/geoj.12065.

23. Gidlow CJ, Jones MV, Hurst G, Masterson D, ClarkCarter D, Tarvainen MP, et al. Where to put your best foot forward: psycho-physiological responses to walking in natural and urban environments. J Environ Psychol. 2016;45:22-29; doi: 10.1016/j.jenvp.2015.z11.003.

24. Gesler W. Therapeutic landscapes: an evolving theme. Health Place. 2005;11(4):295-297; doi: 10.1016/j. healthplace.2005.02.003.

25. Kaplan S. The restorative benefits of nature: toward an integrative framework. J Environ Psychol. 1995; 15(3):169-182; doi: 10.1016/0272-4944(95)90001-2.

26. Stigsdotter UK, Ekholm O, Schipperijn J, Toftager M, Kamper-Jørgensen F, Randrup TB. Health promoting outdoor environments - associations between green space, and health, health-related quality of life and stress based on a Danish national representative survey. Scand J Public Health. 2010;38(4):411-417; doi: 10.1177/1403494810367468.

27. Duvall J, Kaplan R. Enhancing the well-being of veterans using extended group-based nature recreation experiences. J Rehabil Res Dev. 2014;51(5):685-696; doi: 10.1682/jrrd.2013.08.0190.

28. Roe J, Aspinall P. The restorative benefits of walking in urban and rural settings in adults with good and poor mental health. Health Place. 2011;17(1):103-113; doi: 10.1016/j.healthplace.2010.09.003.

29. Gatrell AC. Therapeutic mobilities: walking and 'steps' to wellbeing and health. Health Place. 2013;22:98-106; doi: 10.1016/j.healthplace.2013.04.002. 


\section{HUMAN MOVEMENT}

M. Zurawik, Moving through spaces: a narrative review

30. Gatrell AC. Mobilities and health. Farnham: Ashgate; 2011.

31. Hazlitt W. On going a journey. In: Hazlitt W, Table talk: essays on men and manners [Kindle edition]. 2011. Amazon Media EU.

32. Hunt JD. Time of walking. Stud Hist Gardens Des Landsc. 2016;(36)4:297-304; doi: 10.1080/14601176. 2016.1147873.

33. Shores KA, West ST. Pursuing leisure during leisuretime physical activity. J Phys Act Health. 2010;7(5): 685-694; doi: 10.1123/jpah.7.5.685.

34. Doughty K. Walking together: the embodied and mobile production of a therapeutic landscape. Health Place. 2013;24:140-146; doi:10.1016/j.healthplace.2013.08.009. 